\title{
Estudo e Implementação de Transmissão Analógica de Áudio em Banda-base Utilizando Fibras Ópticas Plásticas
}

\author{
Fábio Hott, Rodrigo Pontes, Ricardo M. Ribeiro e João Dias
}

\begin{abstract}
Resumo-Este trabalho tem, como foco principal, o desenvolvimento experimental de um enlace por transmissão analógica de áudio em banda-base utilizando a tecnologia das Fibras Ópticas Plásticas (POFs). Descreve os princípios ópticos da tecnologia POF, ainda pouco explorada no Brasil, e a sua aplicação em ambiente doméstico. Apresenta o esquema do transmissor e do receptor óptico, e mostra a viabilidade de implantação de home networks a custo relativamente baixo, com POFs.
\end{abstract}

Palavras-Chave-Fibras Ópticas Plásticas, modulação e demodulação óptica, redes ópticas, áudio.

Abstract-The main aim of this work is the experimental development of on audio analog link transmission in base-band using the Plastic Optical Fiber (POFs). Describe the optical principles of the POF technology, yet little known in Brazil, and its application in the home environment. Presents the design of optical transmitter and receiver, and shows the feasibility of deployment of home networks for relatively low cost, with POFs.

Keywords - Plastic Optical Fiber, optical modulation and demodulation, optical networks, audio.

\section{INTRODUÇÃO}

Desde o final dos anos 60 tem-se pesquisado a Fibra Óptica Plástica (POF - Plastic Optical Fiber). Entretanto, foi a partir da redução da atenuação das POFs de PMMA (Polimetil Metacrilato) no espectro visível, do desenvolvimento das POFs de índice gradual (1990) e da criação das fibras perfluoretadas de baixa atenuação (1996), que as POFs começaram a despertar interesse e, com isso, o número de aplicações vem aumentando significativamente [1].

Visando abordar uma tecnologia relativamente nova, a proposta deste projeto é utilizar a fibra óptica de plástico para transmitir um sinal de áudio analógico em um enlace ponto-aponto. $\mathrm{O}$ projeto mostra-se pertinente em função das inúmeras aplicações que se pode obter com a utilização da POF. Além da crescente demanda por conexões em alta velocidade, cujas transmissões possuem taxa de transferência muito superior às encontradas atualmente nas instalações domésticas. Este trabalho está organizado da seguinte forma: A segunda seção descreve as características da POF; A terceira mostra o projeto dos circuitos transmissor e receptor e a quarta é dedicado às conclusões e também são apresentadas sugestões de continuidade inerentes à pesquisa realizada.

\section{CARACTERÍsticas das Fibras Ópticas Plásticas}

As POFs apresentam importantes vantagens sobre as GOFs (Glass Optical Fiber - fibras ópticas de vidro). Especifica-

Fábio Hott e Rodrigo Pontes, Departamento de Telecomunicações, Universidade Estadual do Rio de Janeiro. Ricardo M. Ribeiro, Departamento de Telecomunicações, Universidade Federal Fluminense. João Dias, Departamento de Telecomunicações, Centro Federal de Educação Tecnológica do Rio de Janeiro, Rio de Janeiro, Brasil, E-mails: fabiohott@gmail.com, rodrigo.pontes@gmail.com,rmr.rlk@terra.com.br e joaotdias@yahoo.com.br. mente, seu diâmetro, entre $0,25-1 \mathrm{~mm}$, permite que conectores plásticos de baixa precisão sejam usados, o que reduz a complexidade e o custo total do sistema (figura 1). Além disso, POFs se destacam por sua ótima flexibilidade e resistência a impactos e vibrações, assim como pelo ótimo acoplamento da fonte de luz a fibra.

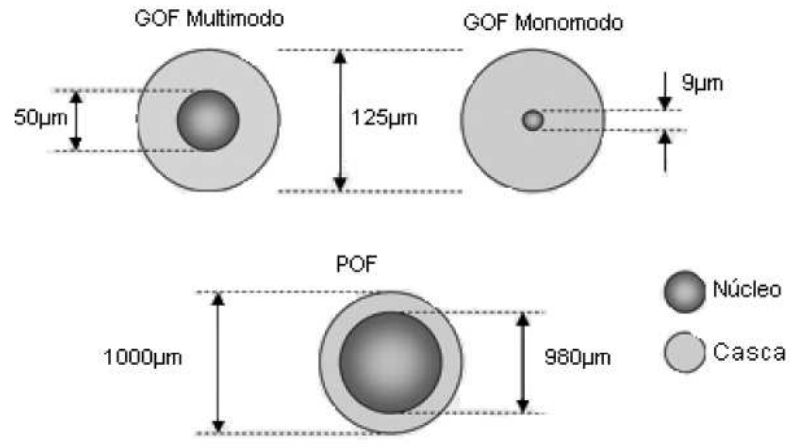

Fig. 1. Comparação de diâmetros de revestimento e núcleo para fibras GOF MM e SM e fibras POF.

As janelas de transmissão das POFs de PMMA são localizadas em 520, 570 e $650 \mathrm{~nm}$, ou seja, se encontram no espectro visível nas cores verde, amarelo / laranja e vermelho (figura 2) [2].

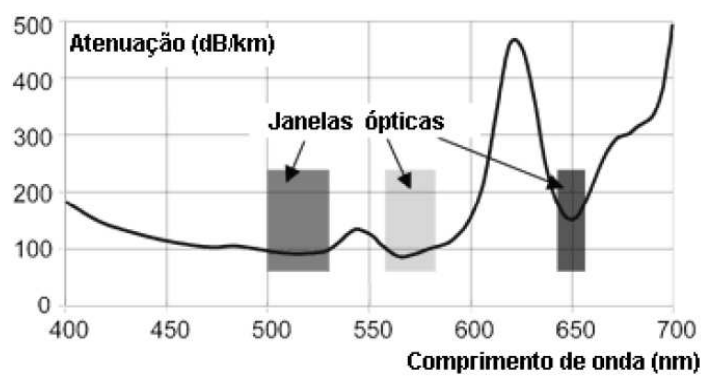

Fig. 2. Espectro de atenuação para POFs de núcleo de PMMA.

Entretanto as POFs PMMA apresentam grande dispersão modal, o que limita o alcance dos enlaces.

\section{Projeto dos Circuitos Transmissor E Receptor}

A figura 3 mostra um esquema genérico de transmissão/recepção de sinais de áudio em banda-base por fibra óptica.

A modulação analógica de um LED, consiste em polarizar o LED com uma corrente DC que permita que toda a excursão 


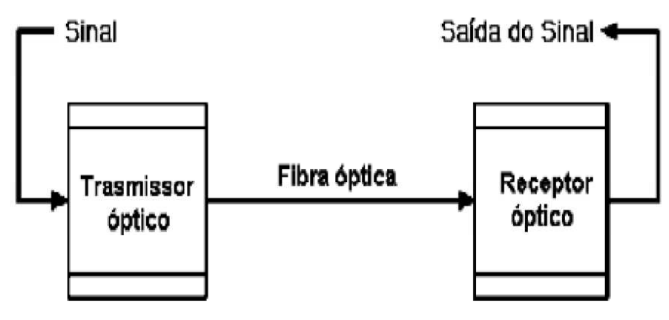

Fig. 3. Esquema genérico de transmissão/recepção de um sinal de áudio em banda-base por fibra óptica

do sinal a ser transmitido passe pela região linear da relação entre potência óptica e corrente do mesmo. $\mathrm{O}$ esquema mostrado na figura 4 descreve o conversor eletro-óptico.

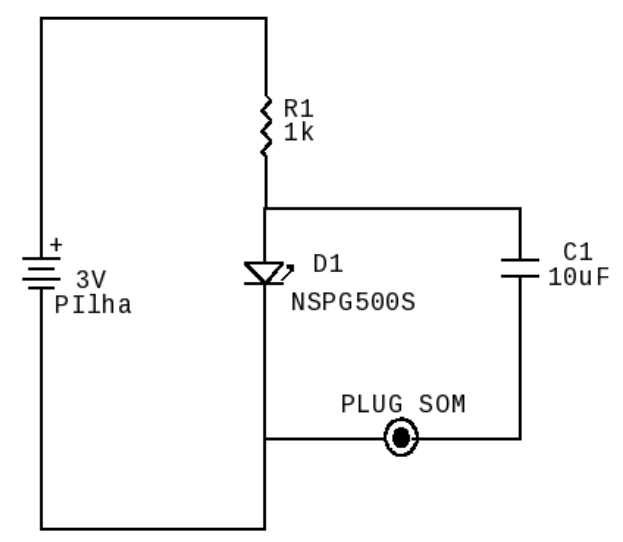

Fig. 4. Esquema do circuito transmissor.

O LED utilizado no experimento, é o NSPG500S de Nitrato de Índio e Gálio (InGaN) de cor verde (525nm). Esse tipo de LED é bastante conhecido como Ultra Brilhante por apresentar intensidade superior à maioria dos LEDs comuns.

A demodulação deve fazer decisões sobre quais tipos de dados foram enviados, baseados em uma versão amplificada de um sinal distorcido, para isso usa-se um fototransistor $I F$ D92 que apresenta resposta entre 400 e $1100 \mathrm{~nm}$ e é indicado para transmissões com largura de banda de $15 \mathrm{kHz}$. O circuito apresentado na figura 5 descreve o conversor ópto-elétrico.

$\mathrm{O}$ enlace foi testado com a transmissão de sinais de áudio à partir de um laptop, como mostram as figuras 6 e 7.

\section{CONClusões E Sugestões}

Com componentes relativamente baratos e implementação eletrônica básica, foi possível fazer transmissão de áudio livre de interferências. Os estudos e pesquisas deste trabalho são base para futuros melhoramentos tais como: utilizar modulação para transmitir mais de um canal de áudio pela mesma fibra (áudio estéreo); com implementação eletrônica mais sofisticada, transmitir vídeo e, áudio e vídeo simultaneamente; com uma conversão eletro-óptica digital e uso de laser em substituição ao LED, fazer transmissão de dados o que permite substituir os cabos UTP nas redes de computadores. Com o advento da TV digital e taxas de dados cada vez maiores em conexões de Internet, vê-se a necessidade de se estudar a implantação das POFs em ambiente doméstico.

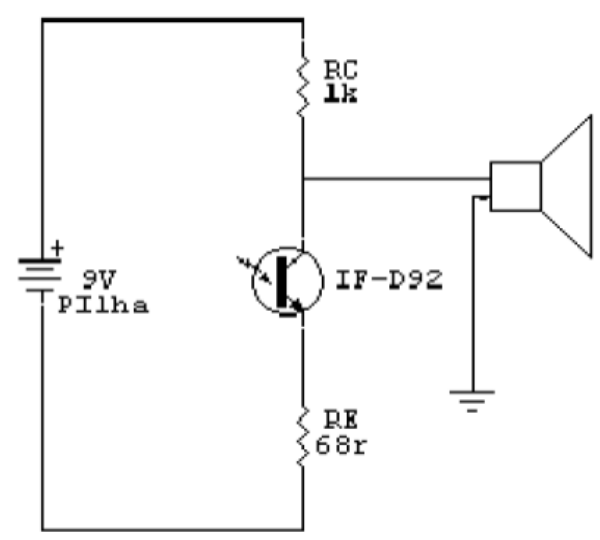

Fig. 5. Esquema do circuito receptor.

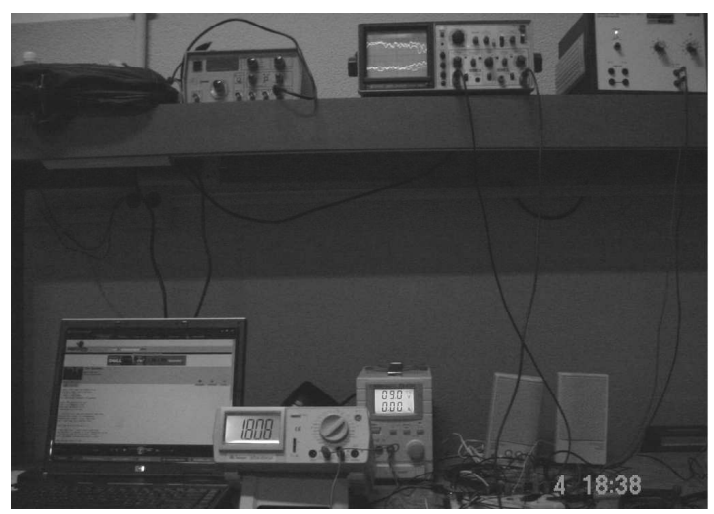

Fig. 6. Análise do sinal de áudio transmitido.

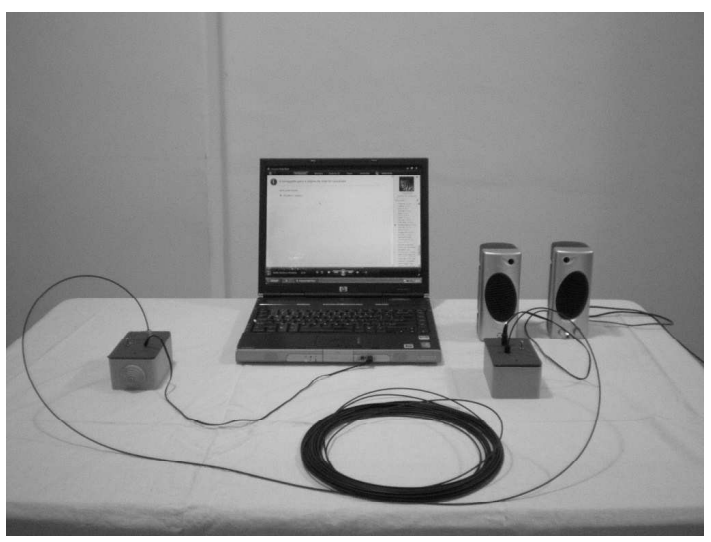

Fig. 7. Enlace de transmissão de áudio em funcionamento.

\section{AgRADECIMENTOS}

Ao Laboratório de Comunicações Ópticas da Universidade Federal Fluminense (LACOP UFF), por nos permitir usar as suas instalações durante o desenvolvimento deste trabalho.

\section{REFERÊNCIAS}

[1] J. Zubia and J. Arrue, "Plastic Optical Fibers: An introduction to their technological processes and application”. Bilbao, Spain, v. 7, n. 2, apr. 2001.

[2] L. Blyler, "Material Science and Technology for POF", Proc. Eighth Conference on Plastic Optical Fibers and Applications (POF99), Chiva, Japan, pp. 196-200, 1999. 